\title{
AdAM SMith Y La VOCACión COMERCIAL de La SIMPATÍA. UNa PROPUESTA DE ANÁLISIS
}

\author{
[ADAM SMITH AND THE COMMERCIAL VOCATION FOR SYMPATHY. A PROPOSAL OF ANALYSIS]
}

Nicole Darat Guerra*

\begin{abstract}
Resumen: El presente artículo se propone explorar los vínculos entre ética y economía en la obra de Adam Smith, tratando de superar la aparente contradicción entre sus dos mayores trabajos: La teoría de los sentimientos morales y La riqueza de las naciones, que diera origen en el siglo XIX a la famosa discusión en torno al Problema de Adam Smith. Lejos de mantener la idea de que ambos trabajos se contradicen, propondremos una interpretación donde la simpatía aparece como un elemento central para explicar el origen de la sociedad comercial que Smith defiende más abiertamente en su famoso tratado de economía política, sin dejar de lado los reparos que el mismo Smith tuviera respecto a las consecuencias morales y sociales provocadas por los patrones culturales promovidos por la sociedad comercial naciente. Palabras Clave: Adam Smith, simpatía, virtud, sociedad comercial, economía política.
\end{abstract}

\begin{abstract}
Abstract: The present article aims at exploring the existent links between ethics and economics in Adam Smith's work, trying to overcome the seeming contradiction between his two major works: The theory of moral sentiments and The wealth of nations, which originated the famous Adam Smith Problem in the $19^{\text {th }}$ century. Far from maintaining the idea that both works are in contradiction, we will propose an interpretation where sympathy appears as a central element in explaining the origin of commercial society defended by Smith more openly in his political economy treatise, without leaving aside the criticisms Smith himself had regarding the moral and social consequences of the rising commercial society's cultural patterns.

Keywords: .
\end{abstract}

KEYWORDs: Adam Smith, sympathy, virtue, commercial society, economy

\section{INTRODUCCIÓN}

$\mathrm{E}^{\mathrm{n}}$ n el presente artículo buscaremos proponer una clave de lectura para entender el aporte de Adam Smith a filosofía moral y política más allá del retrato que se ha construido del filósofo escocés como un acérrimo defensor del libre mercado. El artículo consta de seis partes y una conclusión, a través de las cuales buscaremos probar que la simpatía funciona como un puente entre la antropología benevolente propia de su teoría moral y el hombre autointeresado de la teoría económica. Con todo, a pesar de ser la simpatía la base el juicio moral, puede volverse un mecanismo irreflexivo de sumisión a los patrones de producción de la sociedad comercial, aun al costo de la propia felicidad de los individuos. Hacia el final del texto buscaremos proponer una salida ética consistente con el propio entusiasmo smithiano hacia la sociedad comercial emergente. 


\section{El PROBlema de Adam SMith}

La herencia intelectual de Adam Smith no fue una tranquila recepción textual durante el siglo inmediatamente posterior a su muerte. Una inquietud caracterizó el estudio de su obra: la aparente incongruencia entre la antropología subyacente a su trabajo de 1759, la Teoría de los sentimientos morales, y aquella que se desprende de su influyente tratado económico de 1776, La riqueza de las naciones. Mientras en el primero Smith nos presentaba la figura de un individuo capaz de simpatizar con las circunstancias de sus pares, de conmoverse y condolerse incluso con el dolor de los muertos, en el segundo, su caracterización de la naturaleza humana es la de un individuo auto-interesado, egoísta inclusive, de motivación aparentemente monolítica. Los lectores alemanes del siglo XIX, denominaron esta paradoja como El problema de Adam Smith. Aunque esta discusión ha sido aparentemente abandonada en nuestros días, por una especie de consenso silencioso a favor de la continuidad entre la ética y la economía política en el pensamiento del escocés, los énfasis varían y resulta interesante hacerse la pregunta de si la balanza se inclina a favor de la visión del individuo egoísta, llamado a ser protagonista del surgimiento de la sociedad comercial, o de aquel individuo empático que miraba con recelo, con melancolía quizá, el surgimiento de un contexto que dificultaba el ejercicio de la virtud tal como lo concibiera la tradición.

De acuerdo con D.D Raphael (1), el célebre problema provendría de dos posibles fuentes, la primera de ellas radica en que buena parte de la literatura en torno a Smith proviene de economistas; la segunda, es la falla en notar las transformaciones que experimentó la Teoría de los sentimientos morales, a lo largo de las seis ediciones que vio en vida de Adam Smith y citar fragmentos de la edición de 1756 como si correspondieran a la publicada en 1790, esta omisión no es banal si tomamos en cuenta que La riqueza de las naciones, el texto con el cual se quiere probar continuidad, discontinuidad o subordinación, fue publicado, tal como señalábamos más arriba, durante este lapso de treintaicuatro años. Una consideración histórica del texto-, dirá Raphael quien fuera co-editor de las obras completas junto con A.L Macafie- nos permite constatar la inexistencia de una superación de la antropología de la Teoría, sino más bien la reafirmación de la teoría smithiana de la virtud, aún después de haber publicado su gran tratado de economía política. La evidencia conceptual de esta continuidad abunda al comparar ambos trabajos, por ejemplo respecto del rol asignado a la justicia (TSM II.ii.III.4; $R N$ V.iii.7) y el incesante deseo de mejorar nuestra condición, reconocido en ambas partes como "el gran propósito de la vida humana" (TSM I.iii. II.1; RN II.iii.28).

Como sea, el debate suscitado por los dos mayores trabajos de Smith se ha movido desde la perplejidad del siglo XIX, hacia el dominante consenso de la continuidad que mencionábamos. No obstante este consenso dista mucho de corresponderse con un alineamiento teórico sobre cómo ha de establecerse dicha continuidad, ni dónde hayan de ponerse los énfasis. Para Leonidas Montes, la reducción del debate a una miopía histórica, tal como lo hace Raphael, resulta poco convincente. Según Montes el famoso Problema, no puede simplemente darse por superado y desecharlo como suele suceder con ciertas modas académicas. La lectura de Raphael, aunque ice las banderas de la victoria, se apoyaría en una interpretación restringida de la simpatía, que la subsumiría en el mero juicio moral (Montes, 82), para Montes la simpatía trasciende el mero juicio y es, ella misma motor de la acción, una acción que se desenvuelve también en el ámbito económico, un "sentimiento económico", siguiendo el concepto acuñado por Emma Rothschild, para quien "los sentimientos son 
el objetivo del esfuerzo económico y el complemento del intercambio económico" (9).

Otras posiciones interesantes que el debate sigue arrojando son aquellas que defienden una aparente discontinuidad, como la solución modular propuesta por Vernon Smith, de acuerdo con la cual la simpatía y la benevolencia, sentimientos morales superiores, serían coextensivos a nuestras relaciones íntimas, mientras que el ámbito económico, aquel donde la relación entre extraños es la regla, se regiría por la fría virtud de la prudencia ordinaria y el cálculo que es propio de ella, lejos de la búsqueda de la excelencia que caracterizara a la idea clásica de la virtud. Para Vernon Smith, las disposiciones del carácter relativas a la intimidad bien pueden transitar del lado opuesto de aquellas disposiciones que hacen posible - y aún más, que ponen en marcha- la sociedad comercial. La benevolencia de un lado y el amor propio de otro, se corresponderían con dos niveles diferentes del intercambio: el personal y el impersonal (V.Smith 17)

Nuestra posición en este artículo toma distancia de Vernon Smith y se pone más bien del lado de interpretaciones como la de Montes o de la misma Rothschild, señalando que la simpatía es un sentimiento económico, es decir, que no se trata de compartimentos estancos donde reinan unos sentimientos, mientras que otros quedan vetados. La tesis de la compartimentlización de las motivaciones resulta frágil, pues la conducta repetida en el ámbito económico no tardaría en invadir el ámbito de las relaciones íntimas, debilitando progresivamente nuestra receptividad para los sentimientos morales, tales como la benevolencia, es decir, para cooperar incluso en nuestros intercambios más íntimos (Cfr. Frank et al.). Procuraremos, por el contrario, entender la simpatía como un sentimiento moral que nos lleva del ámbito íntimo hacia el mercado, no solo en cuanto calibrador del juicio moral, sino como el motor de nuestra incontrolable sociabilidad y de la mano de ella, de la producción de la sociedad comercial que Smith señalara como el propósito de nuestra naturaleza.

La vocación comercial de la simpatía

A menudo la opinión pública ha etiquetado a Adam Smith como el padre del libre mercado, y desde ese supuesto lo ha alabado o execrado. El libre mercado y el egoísmo son frecuentemente pensados como dos realidades inseparables y el trabajo de Adam Smith ha sido leído como una contribución clave en esa dirección. No obstante ello, una lectura cautelosa de los textos del filósofo escocés nos revela que dicha exaltación de la libertad de comercio, no carecía de una visión crítica respecto de los efectos del desarrollo económico que dicha libertad conllevaba.

La defensa de la sociedad comercial propia de la modernidad temprana, y que encontramos en Adam Smith, pero también en David Hume y en el otro lado del canal de la Mancha, en Montesquieu, es a menudo vista como una proto-defensa de la sociedad burguesa y sus valores, o de la pérdida de los valores tradicionales que esta representa. La famosa Fábula de las abejas de Mandeville era la responsable de que el vínculo entre sociedad comercial y egoísmo ganara cierta notoriedad y que el mismo Smith buscara refutarlo desde las primeras líneas de su Teoría de los sentimientos morales, basta con recordar las palabras que abren el texto: "Sin importar cuán egoísta se pueda suponer a un hombre, evidentemente hay algunos principios en su naturaleza, que lo interesan en la fortuna de otros, y hacen su felicidad necesaria para él, aunque no obtenga nada de ella salvo el placer de observarla". (TSM I.i.I.1). De acuerdo a Bert Kerkhof (219 y ss.) y Pierre Force (14) que lo sigue en este punto, Smith parece estar argumentando directamente en contra de Mandeville y su exaltación del egoísmo y el vicio en la conocida fábula. El autor de la Fábula también había sido blanco de las críticas de Hume . 
La asunción del interés propio tenía el estatus de un axioma en los días de Smith, un estatus que provenía de la pregnancia del principio en todas las explicaciones contractualistas de la conducta humana popularizadas por las teorías del derecho natural, cuyo punto de partida era el estado de guerra al cual los individuos llegan por causa de su natural e incorregible egoísmo, asunción compartida por la economía mercantilista (Hollander, 137). Por ello, cuando Smith escribe las primeras frases de su tratado de filosofía moral, no está pensando solamente en Mandeville, está pensando también en toda la tradición que había hecho de ese principio el punto de partida innegable de la teoría política y moral al uso. Smith no trata de refutar la suposición de egoísmo, sino de mostrar que la naturaleza humana es mucho más compleja que aquello que una gran parte de la teoría política de la época había sentenciado. La segunda parte de la cita smithiana da cuenta de dicha complejidad: los hombres y tal vez también las mujeres, son egoístas, pero están determinados por la naturaleza a sentir una inclinación hacia sus pares, a interesarse por la fortuna de los demás, esto es, a sentir simpatía (y no solo lástima o compasión, que implican la identificación con la miseria de los otros).

La simpatía es, así, un sentimiento que hace posible todo juicio moral dado que nos conecta a los demás, a los sentimientos que subyacen a su acción. Aprobamos moralmente aquello que consideramos apropiado, y nuestro juicio sobre lo apropiado y lo inapropiado, provienen de la identificación o el rechazo que el mecanismo de la simpatía hace posible. Si yo simpatizo con tu dolor, o con tu alegría, es porque me parecen reacciones razonables ante las circunstancias dadas (TMS I.i.3.I).

La definición de la simpatía como fellow-feeling, como el compartir un sentimiento, nos permite rastrear su parentesco con el concepto análogo del estoicismo, donde por simpatía se entiende el compartir el mismo pneuma o la misma alma o esencia, con alguien o algo, la simpatía en el esquema de Smith es el sentimiento que nos permite, mediante la imaginación, llegar a compartir los sentimientos más profundos de los otros, trascendiendo así el solipsismo aparente de un juicio moral que radica primariamente en el sentimiento. La imaginación juega un rol fundamental y permite que la simpatía pueda ir más allá de los límites de la propia experiencia, incluso más allá de cualquier experiencia posible, tal como es ilustrado a través de dos ejemplos propuestos por Smith: la simpatía con los muertos que subyace a nuestro pesar ante la muerte, y la simpatía con los locos. Ni locos ni muertos tienen conciencia de su condición, y aún así nuestra imaginación nos permite comprender su condición y entristecernos. El proceso cognitivo de la imaginación corrige así la parcialidad propia de la simpatía espontánea, ya que no nos imaginamos cómo, nosotros mismos como espectadores, nos sentiríamos si estuviéramos en la posición del actor, lo que hacemos en cambio es imaginar cómo nos sentiríamos si fuéramos esa persona, con sus experiencias y expectativas y en la misma situación. (TMS II.i.3.I) Para Smith el surgimiento de la sociedad comercial no iría de la mano de una decadencia moral, ni mucho menos de la exaltación del vicio como motor del progreso à la Mandeville.

La suposición de la simpatía, en lugar del interés propio como base de la moral, no es simplemente el reemplazo de un principio atomista, por otro principio atomista originado en el aislamiento de un yo cerrado sobre sí mismo, que sale al encuentro con los otros. Este mecanismo, de acuerdo con Smith, y con la tradición sentimentalista de la que es heredero (Vid. Seoane 2004) hace que busquemos la aprobación de nuestros pares y que modifiquemos nuestra conducta para obtener su aceptación. La clave de lectura que proponemos aquí para reconstruir una continuidad entre la antropología subyacente a La riqueza de las naciones, y el sujeto simpático de la Teoría de los sentimientos morales, se apoya precisamente en este rasgo de la simpatía que configura 
el omnipresente deseo de ser amados.

La teoría moral smithiana, llama nuestra atención sobre la transformación de la moral que va de la mano con la transformación de la sociedad, de una de agricultores, a una de comerciantes, una transformación de la virtud que se desplaza de la excelencia cívica a la búsqueda de la justicia, entendida como la satisfacción de las necesidades básicas, aun al costo de la desigualdad (Hont 2005 395, 396). Esta transformación de las jerarquías de la virtud que la tradición considerara inamovibles, con todo, no es vista por Smith, sin un dejo de congoja. Esta cita de La teoría de los sentimientos morales, da cuenta de ello:

Es porque la humanidad está dispuesta a simpatizar más enteramente con nuestra alegría que con nuestra pena, que exhibimos nuestras riquezas, y escondemos nuestra pobreza. Nada es más mortificante que ser obligados a exponer nuestro sufrimiento a la vista del público, y sentir que a pesar de que nuestra situación está expuesta a los ojos de toda la humanidad, ningún mortal concibe la mitad de lo que sufrimos. Es más, es principalmente por esta consideración hacia los sentimientos de la humanidad que perseguimos la riqueza y evitamos la pobreza. ¿Para qué fin es todo el ruido y ajetreo de este mundo? ¿Cuál es la finalidad de la avaricia y la ambición, de la búsqueda de riquezas, de poder y preeminencia? ¿Es para suplir las necesidades de la naturaleza? El salario del trabajador más miserable podría suplirlas. (TMS I.iii.II.1)

Smith se pregunta por el propósito del ajetreo y la inquietud de este mundo, la respuesta podemos encontrarla dentro de su mismo trabajo: la construcción y el mantenimiento de la sociedad comercial, aquella donde el más miserable de los trabajadores puede satisfacer sus necesidades básicas. Queremos ser amados, queremos que se simpatice con nosotros, y sabemos, en cuanto somos capaces de ponernos en el lugar de los otros, que la alegría es mucho más apta para la simpatía que la tristeza, es aquella la que produce la conexión placentera con los otros, salvo que, por supuesto, se convierta en el objeto de la envidia, entonces su efecto es el contrario de aquel que buscamos. Para el escocés, ser objeto de envidia no es el resultado que perseguimos a través de nuestras ansias de simpatía, pero tampoco lo es la mera acumulación de riquezas, lo que buscamos conscientemente es la simpatía de nuestros pares. El ajetreo de este mundo por el cual Smith se pregunta, no busca satisfacer nuestras necesidades básicas, ni tampoco proveernos de felicidad a través de la mejora material de nuestra condición, pues seríamos mucho más felices si no tuviéramos que dedicar nuestras energías y todo nuestro tiempo y afecto a obtener y cuidar todas esas riquezas innecesarias y el estatus que estas proveen. Pero en nuestra búsqueda de esa conexión simpática con otros, damos origen a la sociedad comercial, el único lugar en que la felicidad es posible de acuerdo con el escocés, sin proponérnoslo. Es la Naturaleza o el Autor de la Naturaleza quien nos guía.

\section{LA MANO INVISIBLE de LA NATURALEZA}

La famosa metáfora de la mano invisible no debe buscarse únicamente en La riqueza de las naciones, como justificación de la deseabilidad de un mercado desregulado. Antes bien, como herramienta epistemológica, su presencia puede ser encontrada también en la Teoría de los sentimientos morales e incluso más tempranamente en la Historia de la astronomía. El lugar ocupado por la Naturaleza o su autor (términos que Smith usa indistintamente), es precisamente el de un mecanismo de mano invisible, mediante el cual las transformaciones ocurren por la acumulación de 
acciones individuales sin un propósito prefijado.

Me gustaría llamar la atención sobre una sección de la Teoría de los sentimientos morales donde esto se hace particularmente evidente. Permítaseme citar en extenso:

El truhán esforzado cultiva el suelo; el hombre bueno indolente lo deja sin cultivar; ¿quién debe recoger la cosecha? ¿Quién debe morir de hambre y quién vivir en plenitud? El curso natural de las cosas decide en favor del truhan: los sentimientos naturales de la humanidad en favor del hombre de virtud. El hombre juzga, que las buenas cualidades de uno están grandemente sobre-recompensadas por esas ventajas que tienden a procurarle, y que las omisiones del otro están por lejos muy severamente castigadas por las penurias que naturalmente le traerán; y las leyes humanas, las consecuencias de los sentimientos humanos, le quitan la vida al esforzado y cauto traidor, y compensan, con extraordinarias recompensas, la fidelidad y el espíritu público del imprudente y despreocupado buen ciudadano. Así el hombre es guiado por la Naturaleza a corregir, en alguna medida, la distribución de las cosas que ella misma habría de otro modo hecho. Las reglas que ella misma lo impulsa a seguir, son diferentes de aquellas que ella misma observa (...) Las reglas que ella sigue son adecuadas para ella, aquellas que él sigue son adecuadas para él: pero ambas son calculadas para promover el mismo gran fin, el orden del mundo y la perfección y felicidad de la naturaleza humana. (TMS III.V.9).

El pasaje anterior puede ser leído en dos claves diferentes: la primera de ellas nos revela a un Smith que pretende distinguir tajantemente la virtud cívica tradicional, de las virtudes de la sociedad comercial, inexorablemente vinculadas al trabajo y el enriquecimiento personal y de espaldas a la tradicional idea de una "persona virtuosa". Para Peter McNamara, la cita de la Teoría expresa la defensa smithiana de la tesis de que una sociedad corrupta puede funcionar y aún más, que Smith mismo abogaba por un tipo de sociedad que estaba llamado a minar la virtud estricta (McNamara 1996, 127). Esta lectura no deja de constatar un aspecto importante del pensamiento de Smith, sin embargo en este trabajo exploraremos una segunda lectura de la cita anterior, que pone en tela de juicio la supuesta defensa irrestricta de una sociedad donde solo pudieran hallarse las virtudes medianas de la prudencia corriente y la laboriosidad.

Esta segunda interpretación toma el hilo del concepto de Naturaleza, una naturaleza que al parecer se mueve de maneras misteriosas. Podemos encontrar indicios para resolver este misterio en el párrafo antes citado. En una lectura cuidadosa de este, se leen los resultados de una acción desarrollada en tres niveles: el primero, aquel donde la Naturaleza, entendida como el conjunto de las leyes físicas que establecen las causas y las consecuencias en el mundo; esto es, el hombre que cultiva el suelo es aquel que debe recoger la cosecha pues es el producto de su trabajo. El segundo nivel es aquel de los sentimientos humanos y del juicio moral que proviene de ellos, para el cual la virtud aparece como un factor determinante en la distribución de la riqueza, y dado que las leyes, se dice, son la expresión de los sentimientos humanos, los seres humanos buscan corregir las consecuencias de la causalidad natural, quitándole la vida al traidor prudente y compensando la virtud del imprudente buen ciudadano. El tercer nivel, en tanto, es el resultado de una torsión de la cadena causal, un giro que es hecho por las leyes humanas, es la voluntad última de la Naturaleza, por lo que sin importar lo que hagamos estaremos siguiendo los planes de esta. La sociedad comercial es, en este sentido, un resultado no intencional de las acciones humanas, así podemos decir que es la Naturaleza quien da un sentido general al ajetreo y bullicio en esta vida, del mismo modo que la Providencia reinaba el cosmos estoico, guiando a los que se dejan y arrastrando a los que se resisten. En palabras de Glenn Morrow: 
La confianza de Adam Smith en la "naturaleza" y en "la mano invisible" debe ser tomada como más que una fe deísta en la armonía y beneficencia del universo. Es un reconocimiento del orden social como una expresión completa de la vida individual y como una unidad orgánica que se mantiene independientemente de la voluntad de los individuos. Es, además, un reconocimiento de que la sociedad es una gran realidad histórica para cuya contención, las voluntades de los hombres particulares, tanto de hecho como de derecho, son relativamente impotentes. (Morrow 33)

La sociedad, de acuerdo con Morrow, es esa gran realidad que excede las voluntades individuales, aquella realidad para cuya explicación Smith recurre al dispositivo de la mano invisible de la Naturaleza. Pero la fuerza inquebrantable de la mano invisible de la Naturaleza pareciera hacer de las acciones individuales, un esfuerzo estéril y del engaño al que ella nos somete, un medio para sus fines superiores, un secreto inaccesible para los individuos que actúan e interactúan en la sociedad. En el esquema propuesto de tres niveles, podríamos encontrar la moral —al igual que la ley humana, fundada en nuestros sentimientos naturales - en aquel segundo nivel, aquel donde nuestros sentimientos juzgan la causalidad dada de la Naturaleza e intentan modificarla a través de la acción. En el caso de la búsqueda de riquezas, lo que juzgamos son las necesidades naturales, aquellas que pueden ser satisfechas incluso por las rentas más bajas, pero cuando se trata de las riquezas, nuestros sentimientos naturales nos engañan y en lugar de elegir la superioridad de la virtud, elegimos la de la abundancia material, realizando así, el fin último de la Naturaleza, que no está en la satisfacción de nuestras necesidades básicas, ni en nuestra felicidad privada, sino principalmente en el surgimiento de la sociedad comercial, el medio más apropiado para la consecución de la felicidad colectiva.

A pesar de la apariencia mandeviliana del argumento, Smith está muy lejos de afirmar que la sociedad comercial se sostenga en el vicio, pues, si bien nuestra búsqueda de riquezas y bienestar se basa en nuestro deseo de ser amados, también queremos ser amados por las razones correctas, queremos ser un objeto apropiado del afecto de los demás, y esta es la gran diferencia entre el amor propio o incluso el interés propio, y la mera vanidad. Las relaciones de co-dependencia que atraviesan la sociedad comercial tal como Smith la concibiera, son producto de nuestra natural tendencia al intercambio, tanto social, como económico, y considerarlas viciosas solo podría ser reflejo de un resabio conservador latente en el pensamiento de un provocador como Mandevillle, que lleva a Smith a emparentarlo con Rousseau, en su famosa carta a la Edinburgh Review (EPS Lett. 250, 251): ninguno de los dos considera la sociabilidad como algo natural, sino más bien como una especie de lamentable accidente. Para el escocés, la vida en sociedad no es sinónimo de degeneración, sino el punto de partida de toda virtud y del desarrollo mismo de la sociedad.

Smith se apoyará en la idea de una sociabilidad natural, y de una capacidad para la simpatía, que nos hace natural, y por ende, inevitablemente, interesarnos en el destino de quienes nos rodean. No obstante, las diferencias con este otro gran pensador de la mano invisible que fuera Mandeville, no acaban en el develamiento de la treta del vicio privado, pues si bien ambos coinciden en que la contribución de cada individuo al bien común no necesita responder a una intención consciente de promoverlo, la valoración que uno y otro hacen de la acción inscrita en dicho mecanismo, es distinta. Mientras para Mandeville pareciera no haber prosperidad más que en el vicio, y la siempre falsa beatería solo podría conducir a la ruina, para Smith en cambio, junto a la acción inconsciente de los individuos entregados a cuidar de sí mismos, es posible, al menos 
pensar, la promoción consciente de un bien común, más allá de la inmediatez del cálculo costo-beneficio, de aquello que podría distinguirse como "prudencia ordinaria" (Griswold 1999, 203). Incluso las personas más banales podrían hacer una contribución ciega a la sociedad persiguiendo únicamente la riqueza en busca de un falso reconocimiento, el individuo virtuoso, en tanto, se corresponde con aquel que se deja guiar de la sentencia estoica, siendo conducido por la Naturaleza y no meramente arrastrado por ella. Aquel que entiende los fundamentos del funcionamiento de la sociedad, que logra ver más allá de la contingencia aparente de los sucesos.

¿Cuál es, sin embargo, la importancia de ser virtuosos en este contexto? Atendiendo al esquema propuesto, podemos inferir que la virtud genuina, y no meramente la prudencia implicada en nuestro autocuidado, permitiría trascender el segundo y el tercer nivel, aquellos donde el engaño de la naturaleza tiene lugar. Sin embargo, suprimir el segundo nivel, aquel del juicio, puede parecer una renuncia completa a la moralidad y una sumisión total a la causalidad, haciendo de nosotros meros seres naturales, es decir, seres entregados a la causalidad inexorable de la naturaleza. No se trata realmente de deshacernos del juicio, sino juzgar mejor, valorar más la virtud que la riqueza y así, volvernos el objeto correcto del amor y la simpatía, y valorar a los demás del mismo modo. Un gesto propio del sabio estoico, una figura que gravita sobre el pensamiento de Smith y de la que diremos algo más adelante.

Pero la simpatía no solo contribuye al desarrollo material de la sociedad comercial a través de sus productos no intencionados, esta también proporciona las actitudes necesarias para el buen funcionamiento de la sociedad comercial, haciéndola estable y ordenada. El espectador de una determinada acción, se esfuerza a través de la simpatía en adecuar sus propias emociones a aquellas del actor que despierta su fellowfeeling, el actor, por su parte, modera sus emociones para hacer que se ajusten a una versión aceptable por el espectador. La simpatía es entonces un ejercicio de la imaginación, no una pasión autorreferente donde nos imaginamos cómo nos sentiríamos si tal alegría o tal sufrimiento, fuesen nuestros. Cuando simpatizamos con otra persona, nos imaginamos siendo esa persona, no importa cuán distante pueda estar de nuestras circunstancias o de nuestro modo de enfrentarlas. Cuando simpatizamos con otros ejercitamos la virtud de la humanidad, una virtud que Smith calificaba como "suave", mientras que al modular nuestra propia pasión frente a otros espectadores, ejercitamos la virtud del auto-control (self-command), una virtud más heroica. Smith quiere mostrarnos que la sociedad comercial tiene sus propias virtudes.

Para Charles Griswold las analogías, entre el proceso de la simpatía tal como Smith lo describe, y las interacciones entre compradores y vendedores en el mercado, son claras:

A menudo escribe como si la simpatía entre las personas fuera un proceso de ajuste continuo, una búsqueda continua de equilibrio. El consenso (o simpatía mutua) alcanzado en cualquier punto entre dos o más personas puede ser caracterizados desde un punto de vista smithiano como una ficción o relato con esta o aquella historia de acomodaciones y exigencias de comprensión, exigencias que no necesitan ser ilusorias pero que legan a ser confiables solo después de someterse desafíos reiterados en varios contextos. Es un proceso con analogías en la esfera económica, no solo respecto a la importancia del equilibrio en la oferta y la demanda (como se expresa en el precio) sino más generalmente respecto de la importante dimensión retórica de comprar y vender. (Griswold, 102, 103)

El mecanismo de la simpatía no solo tiene un componente retórico que puede resultar finalmente útil para los intercambios mercantiles, sino que es el cemento que 
mantiene cohesionada a una sociedad cuya forma de vida está anclada en la dependencia. La propensión a transportar, trocar e intercambiar, que da origen a la división del trabajo (WN I.i.1) está "más probablemente" fundada en nuestras facultades de razonamiento y discurso, esto es, en nuestra capacidad de comunicar nuestras necesidades, una capacidad fundamental para asegurarle la subsistencia al animal que, como ningún otro, no se hace completamente independiente una vez que ha alcanzado la edad adulta. Los animales humanos aún dependen de otros para satisfacer sus necesidades (ya sean suntuarias o básicas). Pese ello, Smith nunca menciona la simpatía en la Riqueza de las naciones, y podemos asumir que esta ha sido desplazada en el texto de 1776, por la prudencia y la justicia como las virtudes que habrán de limitar los efectos de nuestro egoísmo. Dado que una de las características fundamentales de las interacciones comerciales es que ocurren entre extraños, es muy probable que la simpatía, que nos resultaba indispensable en el resto de nuestras relaciones sociales, se quede corta.

La misma complejidad de la sociedad comercial significa, por una parte, que cualquier individuo necesita asistencia de muchos otros (el mensaje del tosco abrigo de lana) pero, del otro, que solo unos pocos de estos 'muchos' sean conocidos personalmente (...) en una sociedad comercial vivimos predominantemente entre extraños. Las relaciones de amor mutuo y afecto o amistad son correspondientemente, relativamente escasas. Dado que la mayor parte de nuestros asuntos son impersonales entonces deben ser conducidos sobre la base de la adherencia a las reglas de justicia. En una sociedad compleja es improbable que un vendedor sea también tu amigo; para ti el provee algo que quieres, para él tú eres un cliente. (Berry, 9)

Aunque el reconocimiento de nuestra naturaleza simpática nos ha revelado como seres altamente dependientes, y caracteriza toda una comprensión de la sociabilidad, no solo como un accidente que le ocurre a un yo desencarnado, sino como un hecho constitutivo de la moralidad, a pesar del reconocimiento que Smith hace de esto, la simpatía se queda corta cuando se trata del tipo de relación social que caracteriza la sociedad comercial. El engaño de la naturaleza que ocurre mediante nuestro deseo de ser amados, y la búsqueda de riquezas que este trae aparejada, solo funciona como un propulsor de la actividad económica en la sociedad comercial, no garantiza su funcionamiento ordenado ni la cooperación entre extraños. Será la virtud artificial de la justicia y la virtud inferior de la prudencia las que sirvan mejor al fin de garantizar la cohesión de la sociedad comercial.

\section{JUSTICIA Y BENEVOLENCIA EN LA SOCIEDAD COMERCIAL}

La teoría moral de Smith está basada en una metáfora teatral, donde el actor representa una acción frente a un espectador que juzgará con mayor o menor imparcialidad. Los roles en la acción que tiene lugar en el mercado pueden ser distinguidos con claridad: compradores y vendedores. Dada esta reducción de la esfera de acción podemos esperar también la consiguiente reducción de las motivaciones que tienen lugar aquí también; podemos asumir que el interés propio es la única motivación en el mercado, y la única motivación que puede, de hecho, tener éxito en el mercado. Ciertamente podemos encontrar evidencia de esto en La riqueza de las naciones y no necesitamos hurgar mucho para ello, dado que desde las primeras páginas del libro su autor afirma que para conseguir lo que queremos en la sociedad comercial no necesitamos apelar a la benevolencia del carnicero, del cervecero o del panadero para 
conseguir nuestra cena, sino a su amor propio (self love) (WN I.ii.2). Podemos preguntarnos entonces ¿por qué no deberíamos apelar a su simpatía, si como seres humanos bien podrían identificarse con nuestra hambre, una necesidad básica, algo que ellos mismos han sentido al menos una vez en sus vidas? Smith no hace mención alguna de la simpatía en La riqueza de las naciones, dado que al parecer la simpatía aparece como un sentimiento sabiamente limitado. Pero actuamos en el mercado, tenemos roles y desempeñamos una acción. El mercado es una esfera donde podemos ejercer influencia sobre otros, sobre la satisfacción de sus necesidades. ¿Qué es lo que falta en esta acción como para hacer necesaria la exclusión de la simpatía? El resultado de una economía política basada en los sentimientos naturales de simpatía y benevolencia sería una organización comunal de la misma y no una sociedad comercial liberal.

Desde el comienzo de la Teoría de los sentimientos morales, Smith reconoce que más allá del egoísmo podemos encontrar una tendencia natural a preocuparnos por el destino de los otros y eso da cuenta no solo de la simpatía, sino de la benevolencia que podemos derivar de ella también. Pero los intercambios que ocurren en el mercado están mediados por un precio, la posibilidad misma de fijar un precio implica hacer un cálculo y por ende tomar distancia de los lazos emocionales, de nuestras relaciones personales con los vendedores de mercancías. Esto es lo que desaparece en la esfera económica. Sin embargo Smith no intenta proponer un individuo puramente económico como base antropológica de su teoría. Es preciso entender que para el escocés, tanto el egoísmo como la benevolencia son motivaciones básicas de la conducta humana, y es así como debemos entender el pasaje que abre la Teoría de los sentimientos morales. Aunque no somos únicamente individuos autoiteresados, es el interés propio el que debe guiarnos en nuestro actuar en la esfera económica. No tenemos tiempo para hacerlo de otro modo, y el tiempo parece tener una importancia vital cuando se trata de relaciones de cercanía. Esta es la apariencia de verdad en la concepción mandevilliana que notara Smith en su review.

La Riqueza de las naciones es claramente un tratado de economía política y como tal, su enfoque es fundamentalmente económico. En las propias palabras de Smith:

La economía política considerada como una rama de la ciencia del estadista o legislador, propone dos objetos distintos: primero proveer una renta abundante o subsistencia para el pueblo, o más propiamente permitirles proveer tal renta o subsistencia para sí mismos; y segundamente, proveer al estado o república de una renta suficiente para los servicios públicos. Se propone enriquecer tanto al pueblo como al soberano. (WN IV.i.1)

Entonces, la economía política tiene como preocupación principal la riqueza, tanto pública como privada, y en cuanto ciencia, su pretensión es explicar los hechos sociales con la menor cantidad de principios posibles. Es aquí donde el interés propio aparece como el principio explicativo fundamental, de la conducta humana. Podemos distinguir claramente el intento de establecer una disciplina por medio de la identificación de su objeto, disipando así, cualesquiera dudas de a quién están dirigidos sus productos: la economía es la ciencia del estadista o el legislador. La economía es para Smith economía política, y es por dicha razón que en esta esfera de interacciones es más apropiado esperar justicia que benevolencia. Este hecho es ya notado en la Teoría de los sentimientos morales.

Pero aunque la asistencia necesaria no debería ser a partir de motivos tan 
generosos y desinteresados, aunque entre los diferentes miembros de la sociedad no haya amor mutuo ni afecto la sociedad, aunque menos feliz y agradable, no sería necesariamente destruida. La sociedad puede subsistir entre diferentes hombres, como entre diferentes mercaderes, a partir de un sentido de su utilidad, sin ningún amor mutuo o afecto; y aunque ningún hombre en ella deba ninguna obligación o esté ligado por gratitud a ningún otro, seguiría siendo sostenida por el intercambio mercenario de buenos oficios de acuerdo a una valoración acordada. (TMS II.ii.III.2)

La benevolencia se caracteriza por ser libre y por ende por el sinsentido que entraña el intentar forzarla, su ausencia no puede ser objeto de rechazo y por ende no puede ser objeto de castigo. La naturaleza de la justicia, por el contrario, y considerando que Smith sigue a Hume en considerarla una virtud artificial, no pierde su valor al ser forzada. La falta de justicia, a diferencia de la falta de benevolencia, implica un daño, y por ende engendra resentimiento, sentimiento que se encuentra en la base de la justificación del castigo. La justicia entonces, puede ser forzada y su transgresión, castigada (Haakonsen, 86)

En la cita anterior, Smith afirma que la sociedad puede subsistir sin benevolencia como entre distintos mercaderes, sin ninguna simpatía o amor y solo por la utilidad del vínculo, pero no puede subsistir sin justicia. La posibilidad de la subsistencia de una sociedad no virtuosa, como el pueblo de demonios kantiano, tiene como modelo el mercado, el lugar donde la falta de conexión emocional parece ser la regla, así que podemos propiamente concluir que una sociedad sin ninguna simpatía o benevolencia sería completamente como un mercado, pero dado que, como el famoso pasaje de Los sentimientos morales reza, no importa cuán egoístas podamos suponer a los seres humanos, estos tienen la tendencia natural a preocuparse por el destino de los otros. El asunto aquí es que no llevamos esos sentimientos con nosotros al mercado, y mientras el mercado no invada todas las esferas de la vida humana, todavía nos queda un espacio para una interacción plena, para un pleno ejercicio de aquello que de acuerdo con el autor es parte de nuestra naturaleza, si es así, la benevolencia todavía tiene una oportunidad. Somos conscientes, no obstante que este no ha sido el caso, y este optimismo relativo a la posibilidad de separar tan tajantemente ambos dominios de la vida, solo puede explicarse por el escaso desarrollo que el mercado tenía en la época de Smith o por la naturalidad con que los británicos asumieron la transformación de la economía, de agraria a comercial (Appleby 1984, 38 y ss.). Siguiendo la tesis de Rasmussen, Smith se habría tomado en serio el argumento rousseauniano contra la sociedad comercial, constatando que la división del trabajo implica el embrutecimiento de los trabajadores, y la necesidad de un ejército permanente y profesional, que resulta a todas luces peligroso para la sociedad, y que conlleva la pérdida de la valentía como virtud cívica cardinal. Pese esta constatación Smith confía en la prudencia superior del legislador para remediarlos, precisamente porque, con todo, la sociedad comercial es la única capaz de proveer el sostén básico para la mayoría.

Crítica mediante, a Smith le parecía posible la distinción clara de esferas, que se corresponden por ende con un dualismo de virtudes, de un lado están las virtudes éticas cuyo valor recae en que no pueden ser forzadas, mientras que del otro encontramos las virtudes jurídicas o legales que hacen posible nuestra coexistencia en la sociedad. Cuando consideramos la sociedad como es, más que como pensamos que debería ser, la vemos como una sociedad de virtudes medianas aquellas de la prudencia, vigilancia, circunspección, temperancia, constancia y firmeza; pero también podemos observar, aunque menos frecuentemente, aquellas virtudes amables y respetables de la 
benevolencia y el amor de un lado, y de la prudencia superior, el auto-control (selfcommand) e incluso el sacrificio. Sin embargo, estas virtudes no son mutuamente excluyentes - aquí se expresa el corazón de la tesis smithiana - una persona puede también actuar guiada por el interés propio, pero no solo por él, la persona virtuosa necesita la aprobación de los otros, pero puede distinguir la fuente verdadera de felicidad y no ser engañada por la naturaleza. La posibilidad que las virtudes superiores nos ofrecen de establecer esta conexión con los otros, es al mismo tiempo la posibilidad de servir conscientemente los fines de la sociedad, actuando desde la virtud superior, esta es una especie de privilegio para la persona superiormente virtuosa, aquella que se somete al destino en la sentencia estoica. Esta posibilidad, para Smith, está reservada solo para unos pocos afortunados ${ }^{1}$, una especie de aristocracia de la virtud, mientras la mera propiedad de la acción es lo que puede ser alcanzado por la mayoría. A pesar de esto, el buen funcionamiento de la sociedad, y la felicidad pública que le concierne al legislador, no están en peligro dado que los individuos pueden servir el bien común a pesar de su conducta intencional.

El individuo egoísta está sirviendo en realidad fines sociales, aunque su servicio es inconsciente. Ni las virtudes superiores excluyen el interés propio; el hombre perfectamente virtuoso debe preservar su propio bienestar, pero lo hace consciente de la relación entre su propio bienestar y el del todo, y no necesita la mano restrictiva de la ley para decirle cuándo sus intereses deben ser sacrificados. Las virtudes inferiores y las superiores no se oponen entre sí, sino que están profundamente de acuerdo; representan, no solo distintos tipos de acciones, sino distintos niveles de conciencia social (Morrow, 57)

Podemos pensar que la superioridad de la vida moral comparada con la esfera económica, implicaría que en un escenario ideal, esas virtudes del amor y la benevolencia deberían complementar las virtudes de la justicia y la prudencia, pero Smith considera el comercio como una escuela de virtud, no solo del aprendizaje de la independencia al vender nuestra fuerza de trabajo como un bien de mercado, sino en tanto que si un colapso de la simpatía ocurriera - y dado que esto sería un peligro para la estabilidad en tanto la simpatía no es solo una fuente de placer desinteresado, sino un sostén fundamental de la estabilidad ( es la base del respeto de la jerarquía y el rango, a la vez que nuestra simpatía con los muertos es la base del temor al castigo) - las instituciones del comercio, si la simpatía y sus efectos estabilizadores fallaran, podrían proveer la cohesión social que se ha perdido.

A pesar de los diferentes niveles de conciencia y por ende de virtud, hay un vínculo entre la esfera moral y aquella del intercambio comercial: el fin al cual ambas apuntan: la felicidad. Smith es muy claro en señalarlo.

Todas las constituciones de gobierno son valoradas solo en la proporción en que tienden a promover la felicidad de aquellos que viven bajo ellas. Este es su único uso y fin. Desde un cierto espíritu de sistema como sea, desde cierto amor por el arte y la complejidad, a veces parece que valoramos más los medios que el fin, y estar ansiosos de promover la felicidad de nuestros pares, más desde una perspectiva de perfeccionar y mejorar un cierto sistema ordenado y bello, que desde un sentido inmediato del sentimiento de aquello que ellos sufren o gozan (TMS IV.i.11)

La felicidad en tanto que fin, es aquello que le da sentido, tanto a nuestro ejercicio personal de la virtud, como la tarea del legislador, no obstante pareciera que el incesante deseo de mejorar nuestra condición, aquel que actuara como motor de la sociedad comercial cuyo éxito es tarea del legislador, atentara contra nuestra natural 
búsqueda de la felicidad. ¿Es compatible este deseo, con la búsqueda de la felicidad? Dicho de otro modo, ¿es compatible el deseo de bienestar material, propio de una sociedad comercial emergente, con el summum bonum de la tradición ética?

\section{LA BÚSQUEDA DE LA FELICIDAD: LEYENDO A ADAM SMITH DESDE LA TRADICIÓN ESTOICA $^{2}$}

Para abordar la cuestión de la búsqueda de la felicidad en la filosofía moral smithiana, y sus tensiones con la economía política, ciencia encomendada al legislador, resulta interesante recordar las palabras de quien fuera pasajeramente un gran amigo de David Hume: Jean Jacques Rousseau. El ginebrino en su Discurso sobre el origen de la desigualdad describía el surgimiento de la sociedad en los siguientes términos

A medida que las ideas y los sentimientos se suceden, que la mente y el corazón
se ejercitan, el género humano continúa amansándose, las relaciones se extienden
y se estrechan los vínculos. Solían reunirse delante de las cabañas o en torno a un
gran árbol: el canto y la danza, verdaderos hijos del amor y del tiempo libre, se
convirtieron en la diversión o, mejor, a ocupación de hombres y mujeres ociosos
y agrupados. Todos comenzaron a mirar a los demás y a querer ser mirado uno
mismo, y la estima pública tuvo un precio. Aquel que cantaba o danzaba el mejor;
el más bello, el más fuerte, el más diestro o el más elocuente se convirtió en el
más considerado, y éste fue el primer paso hacia la desigualdad y hacia el vicio al
mismo tiempo: de estas primeras preferencias nacieron, por un lado, la vanidad y
el desprecio, por otro, la vergüenza y la envidia; y la fermentación causada por
estas nuevas levaduras produjo finalmente compuestos funestos para la dicha y la
inocencia. (Rousseau 2da parte 255-256)

La cita anterior corresponde a la segunda parte del llamado segundo discurso del ginebrino, en ella da cuenta del rechazo de éste frente al efecto de la civilización sobre la bondad natural de la humanidad. La socialización, aunque parece inevitable debido a su propia naturaleza, es el primer paso hacia la omnipresente desigualdad que caracteriza a las sociedades modernas. Nuestra búsqueda de aprobación y reconocimiento nos guía hacia la destrucción de toda la inocencia y felicidad propias de aquel estado salvaje. Las diferencias con Smith en este punto son evidentes, lo que para uno aparecía como la fuente de todo vicio, para el otro aparece como la base del juicio moral. Es precisamente nuestra conexión con los otros lo que nos permite formular juicios morales, lo que nos permite evaluar lo apropiado o inapropiado de un carácter, de una conducta o de una pasión. Sin la presencia de los otros no tendríamos un espejo en el cual mirarnos, no solo porque careceríamos de la información concerniente a las normas sociales o las particulares normas de etiqueta en una determinada situación, sino, sobre todo, porque nos faltaría la imperiosa presencia de los otros, aquella que hace que moderemos nuestras pasiones más agresivas, ecualizando así nuestras emociones en búsqueda de la simpatía efectiva de nuestros conciudadanos o de la aprobación independiente del espectador imparcial , ese "hombre dentro del pecho" que Smith describe como el resultado del intento de tomar distancia de nuestra situación particular, con el fin de juzgar las acciones de los otros simulando una visión "desde afuera", pero que con más precisión deberíamos llamar una visión desde dentro, acercándose a la idea del dios interior de Séneca.

El completo rechazo rousseauniano a los efectos de la vida en la sociedad es lo que nutre la famosa crítica de los Discursos enviada por Smith a la Edinburgh Review (122-135) carta recordada por la provocadora lectura que el escocés hace sobre el 
trabajo de Rousseau, como una nueva versión de la fábula de las abejas de Mandeville, a la que claramente hace referencia en las primeras líneas de la Teoría de los sentimientos morales. Las diferencias entre uno y otro son evidentes, mientras uno alaba los vicios privados en tanto que fuente de virtud pública, el otro estigmatiza la sociedad como el origen de la decadencia humana. De los vicios tanto privados, como públicos, en donde ninguna conversión alquímica del vicio en virtud, puede ocurrir. Para el ginebrino es más bien lo contrario lo que ha tenido lugar a lo largo del desarrollo de la sociedad, todo lo que era naturalmente virtuoso, ha llegado a ser vanidad, un vicio del cual ninguna virtud puede resultar. La aparición de la vanidad que ocurre cuando los hombres comienzan a buscar la mutua compañía, implica, a su vez, su dependencia mutua, una forma de esclavitud, de la cual su única salida es el restablecimiento de la libertad a través del compromiso sustantivo que supone el contrato social "una forma de asociación que defienda y proteja con la fuerza común la persona y los bienes de cada asociado, y por la cual, uniéndose cada uno a todos, no obedezca, sin embargo, más que a sí mismo y quede tan libre como antes". (Rousseau Contrato Libro I, Capítulo VI) Mediante este contrato el hombre puede retener la libertad que tenía antes de entrar en la sociedad, aquella libertad que comenzó a desvanecerse tan pronto como comenzamos a desear ser el objeto del afecto de los otros, la dependencia, para el republicano Rousseau, es la causa de la corrupción moral. Las diferencias entre Rousseau y Smith se hacen evidentes en este punto: la dependencia y la sociabilidad tienen en cada uno, una consideración completamente distinta, lo que para Rousseau es un signo de esclavitud, para Smith es el camino al progreso moral. De acuerdo con West

El buen salvaje de Rousseau pierde su nobleza en el momento en que se hace dependiente de sus pares en el comercio general de la sociedad. El espectador imparcial de Smith es, por el contrario, un instrumento muy sofisticado y a veces cuasi-trascendental. Es un medio no solo para el desarrollo social y psicológico sino también para el progreso moral. (West 61)

Es precisamente en este punto en que Smith encuentra la similitud, por no decir la traducción de la doctrina de Mandeville en la de Rousseau. De acuerdo con el análisis que Smith hace en la mencionada carta, ambos consideran la necesidad de aprobación como una fuente de vicio, fusionando lo que es el resultado del amor propio, con la vanidad. Finalmente solo se diferencian en el tono, lo que para Mandeville produce "la grandeza y la felicidad mundana del conjunto", para Rousseau es el origen de toda la infelicidad y corrupción de nuestros sentimientos, pero lo que busca destacar Smith en este caso es que ambos pensadores juzgan vicioso nuestro deseo natural de agradar a los otros, independiente de qué pueda producirse socialmente a partir de ese vicio. Para Smith, en tanto, buscar la aprobación de nuestros pares es parte de nuestra naturaleza. No es por sí mismo la fuente de toda virtud, pero es aquello que nos lleva a buscar la simpatía de los otros, mediante la práctica de las virtudes medianas e incluso en algunos casos, de las virtudes superiores, pues quien es capaz de las virtudes superiores no solo desea ser amada sino también ser amada por las razones correctas, esto es, ser el objeto apropiado del afecto, y actuar con los demás de modo apropiado, amable, honorable y admirable. Este ideal también parece ser alcanzable para aquellos capaces únicamente de la virtud ordinaria o inferior. Solo las personas superficiales querrían amor y admiración no merecidos.

El amor propio o incluso el interés propio no pueden ser igualados a la vanidad y esto se corresponde con la distinción rousseauniana entre amour de soi y amour propre. 
Siendo el último comparable al self-love smithiano que puede ser la base para una acción virtuosa, mientras que el último se asemeja a la vanidad producto de los vicios la sociedad que Rousseau desdeña y que Smith considera una desviación de nuestro deseo de ser amados. Sin embargo, Rousseau y Smith están más próximos de lo que parecen a primera vista, y para entender esta conexión necesitamos volver sobre ese engaño del cual la Naturaleza nos hace objeto para cumplir sus fines, un engaño que está a la base de la sociedad comercial.

¿De dónde, entonces, surge la emulación que se despliega a través de todos los
rangos de hombres, y cuáles son las ventajas que nos proponemos a través de ese
gran propósito de la naturaleza humana que llamamos mejorar nuestra condición?
Ser observado, que se nos preste atención, ser tomado en cuenta con simpatía,
complacencia y aprobación son todas las ventajas que podemos proponernos
derivar de ella. Es la vanidad, no la comodidad, o el placer, lo que nos interesa.
Pero la vanidad está siempre fundada sobre la creencia de que somos objeto de
aprobación y atención. (Smith TMS I.i.III.16)

Es parte de nuestra naturaleza, al igual que vivir en sociedad, el desear mejorar nuestra condición. Smith, a diferencia de Rousseau, no sitúa el vicio en la mera conformación de la sociedad, en el mero reunirse alrededor de un árbol, sino en la vanidad que nos hace buscar el mejoramiento en términos únicamente materiales, en circunstancias de que esa elección solo podría traer ansiedad a nuestras vidas, un alejamiento de la tranquilidad que la felicidad, por definición, supone. En nuestra búsqueda de amor y simpatía, solo encontramos desesperación y envidia. Parece que las relaciones sociales, tanto las comerciales como las íntimas, son sostenidas por un engaño. Este es el punto en que Smith y Rousseau coinciden. Pero Smith decide ir más lejos en lugar de considerar desgraciada toda la vida en sociedad .El engaño mediante el cual buscamos la felicidad en el lugar equivocado tiene, no obstante, el resultado de producir las condiciones para la felicidad pública: la economía de mercado que hace posibles nuestras libertades. La genuina felicidad privada solo puede ser lograda una vez que venzamos la ilusión de la naturaleza. Esta opción parece estar más bien al alcance de pocos, de aquellos que son capaces de ver a través de esa ilusión. Con todo, Smith reconoce que solo somos capaces de ver con claridad en la vejez o cuando estamos enfermas y en las proximidad de la muerte.

Tomando en cuenta estas observaciones, podemos preguntarnos si es esto acaso lo que él llamó la filosofía esplenética. Smith hace mención a este concepto dos veces en la Teoría de los sentimientos morales, refiriéndose aparentemente al estoicismo, en tanto su doctrina implica la renuncia a la ilusión que nos mueve hacia el progreso material, tan común en la vida cotidiana. Una filosofía que muchas veces considera antinatural sobre esta misma base, pero la naturalidad que se le opone solo puede ser percibida como tal desde la perspectiva del engaño. Así que cuando afirma que "El plan y sistema que la Naturaleza ha diseñado para nuestra conducta, parece ser completamente diferente al de la filosofía estoica" (Smith TMS VII.iii.I.43) no está diciendo que la doctrina estoica sea implausible, o impracticable, lo que está diciendo es que es contra-natural, dicho de otro modo, que las enseñanzas del estoicismo parecen permitirnos contrarrestar el efecto de la Naturaleza sobre nosotros. Un poco más adelante en el texto escribe:

Los razonamientos de la filosofía, podría decirse, aunque puedan confundir y dejar perplejo al entendimiento, nunca podrán romper la conexión necesaria entre las causas y sus efectos. Las causas que naturalmente excitan nuestros deseos y 
aversiones, nuestras esperanzas y nuestros miedos, nuestros goces y nuestras penas, se producirían, sin duda, a pesar de todos los razonamientos del estoicismo, en cada individuo, de acuerdo con el grado de su sensibilidad, sus propios y necesarios efectos. Los juicios el hombre dentro del pecho, como sea, pueden ser grandemente afectados por esos razonamientos, y el gran recluso puede ser conducido por ellos a intentar superar todas nuestras afecciones privadas, parciales y egoístas, hacia una tranquilidad más o menos perfecta. Dirigir los juicios de este recluso es el gran propósito de todos los sistemas de moralidad. (Smith 1982, 293)

El análisis en tres niveles que hemos propuesto, puede servirnos para echar luz sobre las líneas precedentes: el primer nivel de la naturaleza, aquel de las causas y los efectos, no puede ser cambiado por la filosofía, pero el segundo nivel, aquel de nuestro juicio, puede ser efectivamente afectado por las enseñanzas de esta, esto es, aunque no podamos cambiar la causalidad natural, podemos cambiar nuestra evaluación de esta. Podemos darnos cuenta de que la felicidad reside en la virtud y no en la riqueza, que nuestra necesidad de simpatía se satisface mejor mediante el amor a nuestros pares que por la vanidad, etc. Pero aún queda el tercer nivel, aquel de los efectos que la Naturaleza busca producir a través de nuestros sentimientos morales, a saber, la riqueza y el desarrollo de la sociedad. Smith no es ingenuo a este respecto. No cree en ninguna solución milagrosa, esto es, la Naturaleza por sí misma puede producir efectos sociales adversos, como el efecto negativo de la división del trabajo en los obreros. Él reconoce que esta puede embotar la inteligencia y mutilar la moral del individuo, un individuo así corroído es a penas capaz de las virtudes inferiores. Llegados a este punto, la modificación de los efectos de la naturaleza no le corresponde a la filosofía, sino a la tarea del legislador, a quien está dirigido La riqueza de las naciones. Las instituciones como la educación pública y los impuestos pueden hacer la diferencia.

\section{CONCLUSIONES}

Es nuestro natural deseo de ser amados lo que nos lleva a buscar parecerle agradables a los otros en sus propios términos. En una sociedad cuya prosperidad se sostiene sobre determinados patrones de consumo y de ostentación, como la emergente sociedad comercial de la que habla Smith, nuestro deseo de ser reconocidos pos nuestros pares debe servirse del consumo y la ostentación. Con todo, Smith es consciente de que la búsqueda de la felicidad por ese camino es un engaño que solo puede terminar en mayor ansiedad y disminuir nuestra posibilidad de ser felices, reconoce que esta actúa como aliciente de la productividad en la sociedad comercial. Cada individuo hace una contribución ciega al proceso inevitable de la consolidación de la sociedad comercial, que a juicio del mismo Smith podrá no ser la más igualitaria, pero es sin duda la más justa.

Una lectura de la sociedad comercial desde la teoría moral smithiana nos muestra que esta es una realidad social inevitable y que no podemos oponernos a ella, pero la sumisión ciega no es la única opción. La virtud de la prudencia superior, aunque excepcional en la sociedad comercial, no es imposible. De la lectura de $T M S$ podemos colegir que esta es la virtud del legislador, una figura excepcional, aquel que está llamado a entender el devenir e incluso corregir los efectos adversos de la Naturaleza.

Esta propuesta de lectura nos muestra a un Adam Smith sensible a los fallos de la sociedad comercial, pero a la vez confiado en sus ventajas. Una confianza que se 
basa en la utilidad de la sociedad comercial para la prosperidad, pero también en la posibilidad de transformar el decurso de la causalidad natural que está en manos de quienes son capaces, mediante la virtud, de trascender la sujeción ciega al progreso material.

\section{BIBLIOGRAFÍA}

Joyce Appleby, Capitalism and a new social order the republican vision of the 1790s. New York: New York University Press, 1984.

Berry, Christopher J. «Adam Smith's moral economy». The Kyoto Economic Review 79.1 (2010): 2-15.

Robert H Frank, Thomas Gilovich. «Does Studying Economics Inhibit Cooperation? ». Journal of Economic Perspectives 7.2 (1993): 159-71.

Force, Pierre. Self-Interest before Adam Smith. Cambridge University Press, 2003.

Griswold, Charles. Adam Smith and the virtues of enlightenment. Cambridge U.K.;New York: Cambridge University Press, 1999.

Haakonsen, Knud The science of a legislator. The natural jurisprudence of David Hume and Adam Smith. Cambridge: Cambridge University Press, 1981.

Hont, Istvan. Jealousy of Trade: International Competition and the Nation-State in Historical Perspective. Cambridge Mass.: Harvard University Press, 2005.

Hollander, Samuel. «Adam Smith and the Self-Interest Axiom». Journal of Law and Economics 20.1 (1977): 133-152.

Kerkhof, Bert. «A fatal attraction? Smith's theory of moral sentiments and Mandeville's fable». History of Political Thought 16.2 (1995): 219-233.

McNamara, Peter. «Prudent Men or Industrious Knaves? A Clarification of an Aspect of the "Adam Smith Problem. » Southeastern Political Review 24.1 (1996): 115-135.

Montes, Leonidas. «Das Adam Smith Problem: It's Origins, the Stages of the Current Debate, and One Implication for Our Understanding of Sympathy». Journal of the History of Economic Thought 25.01 (2003): 63-90. . «Adam Smith as an eclectic Stoic», Adam Smith Review, vol. 4, pp. 30-56

Morrow, Glenn. The ethical and economic theories of Adam Smith,. New York: A.M. Kelley, 1969.

Raphael, D. D. The Impartial Spectator Adam Smith's Moral Philosophy. Oxford: Oxford University Press, 2007.

Rasmussen, C. The problems and promise of commercial society. Adam Smith's response to Rousseau. Pennssylvania, Pennsylvania State University Press2008

Rothschild, Emma. Economic sentiments: Adam Smith, Condorcet, and the Enlightenment. Cambridge Mass.: Harvard University Press, 2001.

Smith, Adam. "A Letter to the Authors of the Edinburgh Review». The Edinburgh Review, for the Year 1755. London: 1818. 122-135.

Smith, Adam. An inquiry into the nature and causes of the wealth of nations. Indianapolis: Liberty Fund, 1981.

Smith, Adam. The theory of moral sentiments. Indianapolis: Liberty Fund, 1982.

Waszek, Norbert. «Two Concepts of Morality: A Distinction of Adam Smith's Ethics and its Stoic Origin». Journal of the History of Ideas 45.4 (1984): 591-606.

West, E. «Adam Smith and Rousseau's Discourse on Inequality: Inspiration or Provication?». Journal of Economic Issues 5.2 (1971): 56-70.

\section{Notas}

1 Este es tal vez el punto de convergencia más importante entre Smith y el estoicismo. De acuerdo con Waszek: "El significado general de la 'propiedad' smithiana, para definir un 
nivel de mérito relativo entre las acciones no-virtuosas, imprudentes, ciertamente refleja la concesión estoica de una subdivisión de la clase de acciones imperfectas. El énfasis de Smith en un nivel generalmente alcanzable de propiedad, como opuesto a los casos raros de virtud perfecta, también puede ser visto como haciendo eco a la atención especial que prestaban los estoicos romanos al medium kathekon, convenientia o commune officium. La forma particular en que Smith decide sobre la propiedad o impropiedad de cualquier acción de acuerdo con la simpatía o falta de simpatía con la que el 'espectador imparcial' de Smith muestra- es sin duda independiente de las teorías estoicas y tiene que ser visto como la propia contribución de Smith a la teoría ética." (Waszek 605)

2 Para una perspectiva diferente sobre la influencia estoica en Adam Smith véase Montes, 2008. 